\title{
Spontaneous Object Recognition in the Göttingen Minipig
}

\author{
Anette Moustgaard ${ }^{1,2}$, Nanna Marie Lind ${ }^{1,2}$, Ralf Hemmingsen ${ }^{1}$ and Axel Kornerup Hansen ${ }^{2}$ \\ ${ }^{1}$ Department of Psychiatry, H:S Bispebjerg, University Hospital of Copenhagen, Bispebjerg \\ Bakke 23, DK-2400 Copenhagen NV, Denmark; ${ }^{2}$ Division of Laboratory Animal Science \\ and Welfare, Department of Pharmacology and Pathobiology, The Royal Veterinary and \\ Agricultural University, Bülowsvej 17, DK-1870 Frederiksberg C, Denmark
}

\begin{abstract}
Göttingen minipigs were tested in an object recognition procedure based on spontaneous exploration. Eight pigs were exposed to two similar objects in a sample trial and after a onehour delay exposed to two objects, one familiar and one novel, in a test trial. The pigs explored the novel object significantly more than the familiar object in the test trial $(p<0.05)$, thereby showing recognition of the familiar object. Furthermore, habituation of exploration of the familiar object between the sample trial and the test trial was found $(p<0.05)$. The procedure can be useful for testing of spontaneous trial-unique memory in pigs.
\end{abstract}

\section{KEYWORDS}

memory, exploration, habituation, pig

\section{INTRODUCTION}

Traditionally trial-unique memory has been studied in animals using learned behavior. Well-

\footnotetext{
Reprint requests to: Anette Moustgaard, Ph.D., Division of Laboratory Animal Science \& Welfare, Department of Pharmacology \& Pathobiology, The Royal Veterinary \& Agricultural University, Bülowsvej 17, DK-1870 Frederiksberg C, Denmark. e-mail: anmo@kvl.dk
}

known examples are the delayed matching or nonmatching to sample tasks that were initially developed for monkeys (see for instance Mishkin $\&$ Delacour, 1975). The memory for many kinds of stimuli can be tested in such paradigms, but typically spatial positions or visual stimuli, including objects, have been used. There has, however, for many years been a lack of animal tasks that measure spontaneous trial-unique memory. This has especially been a problem in animal models of human brain pathology because human trial-unique memory is usually formed spontaneously and is not a result of training. An important example is episodic memory, namely the memory for life events (Tulving, 1972), a spontaneous trial-unique memory form impaired in human brain disorders such as Alzheimer's disease (Spaan et al., 2003) and schizophrenia (Harvey \& Sharma, 2002).

To address this need, Ennaceur and Delacour (1988) developed a test for spontaneous trialunique memory in rats. The test measures object recognition by the use of spontaneous exploration of objects. In the procedure, rats are initially exposed to two similar objects in a sample trial and allowed to explore the objects freely. Then, after a delay, the rats are exposed to two objects in a test trial, one of the objects familiar from the sample trial and one novel object. The authors found that rats explored the novel object more than the familiar object. This difference in exploration was seen as a measure for recognition of the 
familiar object. Ennaceur and Delacour considered the test to be a test for working memory (trialunique memory) as opposed to reference memory (memory relevant for several trials) in the terminology of Olton (Olton et al., 1979). Versions of the object recognition test measuring for instance configural (Ennaceur \& Aggleton, 1994) and temporal (order) memory (Mitchell \& Laiacona, 1998) were later developed. Lately an object recognition test based on spontaneous exploration has also been published for mice (Dodart et al., 1997).

The learning abilities of pigs have only been scarcely investigated. Pigs can learn visual and spatial discriminations (see for instance Klopfer, 1966), however, and a spatial working memory task in a radial arm maze (Laughlin \& Mendl, 2000). The purpose of the present study was to describe a spontaneous object recognition test for pigs based upon the principles of Ennaceur and Delacour's test. The described test for pigs can potentially be used for testing brain function in pig models of human brain pathology, e.g. models of Alzheimer's disease or schizophrenia. Although pig models of these disorders have not yet been published, pigs are being used increasingly in the field of neuroscience. Pig models of Parkinson's disease (Mikkelsen et al., 1999) and stroke (Sakoh et al., 2000) have recently been published. The object recognition procedure can also be useful for the testing of drug effects.

\section{EXPERIMENTAL}

\section{Subjects}

Eight 13-month old Göttingen minipig boars (Ellegaard Göttingen minipigs, Dalmose, Denmark) were used in the study. The pigs were kept in groups in pens on bedding consisting of shavings, straw, and sphagnum in separate compartments. The pigs were fed restrictedly according to recommendations for Göttingen minipigs (Bollen, 2001) and water was available ad libitum. Although the stable was lit with electric light from 7 a.m. to 3 p.m., natural light also entered stable windows. Before the object recognition experiment began, the pigs had been subjected to other learning experiments, as well as to behavioral observations.

\section{Object recognition test}

Arena and objects. An arena (2.25 X $3.15 \mathrm{~m})$ positioned inside the animal holding area was used for the object recognition test. The floor of the arena was covered with shavings. Solid plastic objects (household objects, approx. $20 \times 20 \times 12 \mathrm{~cm}$ ) were positioned in the two corners of the $2.25 \mathrm{~m}$ wall of the arena, and opposite the entrance. The objects were of the same color and were tied to the wall with steel wire because the pigs would occasionally shake the objects. All objects were cleaned between trials to remove olfactory traces. Pigs were tested from 10 a.m. to $3 \mathrm{p} . \mathrm{m}$. The behavior of the pigs in the arena was recorded on video. In pilot studies we found large differences in the exploration times for different objects (e.g. funnel, atomizer, dustpan). The objects used in the present experiment were chosen from a pilot study comprising four pigs. The pilot study showed a good and relatively equal exploration of the two different objects used in the present experiment (watering can, colander), and no significant exploration bias for any of two arena positions used.

Procedure. Individual pigs were initially habituated for 3 consecutive days to the arena for a daily session lasting $30 \mathrm{~min}$ (the pigs were already familiar with being isolated in the arena from a behavioral observation study). On the testing day individual pigs were initially habituated to the 
arena for $20 \mathrm{~min}$ without objects. The pigs were then let out of the arena for a short while, and two similar objects were fixed to the wall at the selected positions. The pig was then let back into the arena and left for $10 \mathrm{~min}$ of undisturbed exploration of the objects (sample trial). After the sample trial, the pig was let back into its home pen and waited $55 \mathrm{~min}$ before it was habituated to the arena again (without objects) for $5 \mathrm{~min}$. Again the pig was let out of the arena and two objects, one familiar object encountered in the sample trial and one novel object, were tied to the wall at the same positions as in the sample trial. Subsequently, the pig was let into the arena again for $10 \mathrm{~min}$ of undisturbed exploration of the objects (test trial). The novel object was randomized between pigs. In addition, the position of the novel object in the test trial was randomized between the pigs for each of the novel objects. In this way, potential exploration biases regarding objects or positions were made irrelevant for the test.

\section{Data analysis}

The data were recorded by scoring of videotapes. A square zone was drawn on the monitor screen for each of the objects. The zones corresponded to $40 \times 40 \mathrm{~cm}$ zones in the arena. The time the pigs spent with their snout inside the zones was scored as exploration time using stopwatches. Also manipulating objects with the snout or mouth counted as exploration. The exploration trials lasted for $10 \mathrm{~min}$, beginning shortly after a pig arrived in the arena. The scoring of the videotapes was blinded. Testing of data for normality using Kolmogorov-Smirnov one-sample test revealed that not all samples could be considered normally distributed (Pett, 1997). Exploration times were therefore compared using the Wilcoxon signed ranks test. The tests were performed as two-tailed analyses.

\section{RESULTS}

The minipigs explored the novel object significantly more than the familiar object in the test trial of the experiment $(p<0.05)$ (Fig. 1). Habituation of exploration of the familiar object from the sample trial to the test trial was also found, as the pigs explored the familiar object significantly less in the test trial compared with the sample trial $(p<0.05)$ (Fig. 2). The exploration time for the familiar object in the sample trial was calculated as half of the total exploration time in the sample trial in accordance with Ennaceur and Delacour (1988). Contrary to Ennaceur and Delacour, we did not find a significant reduction in the total exploration time from the sample trial to the test trial. As expected from pilot studies, no significant difference between the time pigs spent exploring the two kinds of objects in the sample trial was evident. Neither did any difference in the exploration time of objects placed in the two positions seem to be present. The total exploration times of the individual pigs varied substantially in the sample trial $(25 \mathrm{~s}, 51 \mathrm{~s}, 1 \mathrm{~min} 3 \mathrm{~s}, 1 \mathrm{~min} 52 \mathrm{~s}, 3$ $\min 11 \mathrm{~s}, 3 \min 46 \mathrm{~s}, 4 \min 43 \mathrm{~s}$ and $9 \min 51 \mathrm{~s}$, respectively) as well as the test trial $(27 \mathrm{~s}, 33 \mathrm{~s}, 53$ $\mathrm{s}, 1 \mathrm{~min}, 1 \mathrm{~min} 30 \mathrm{~s}, 2 \mathrm{~min}, 3 \mathrm{~min} 46 \mathrm{~s}$ and $7 \mathrm{~min}$ $20 \mathrm{~s}$, respectively).

\section{DISCUSSION}

We set up a spontaneous object recognition test for pigs and tested the procedure on Göttingen minipigs. Similar to Ennaceur and Delacour's findings in rats, the pigs explored the new object significantly more than the familiar object in the test trial of the procedure, indicating recognition of the familiar object (Fig. 1). Also in accordance with findings in rats, a significant habituation of exploration of the familiar object from the sample trial to the test trial of the procedure was found 


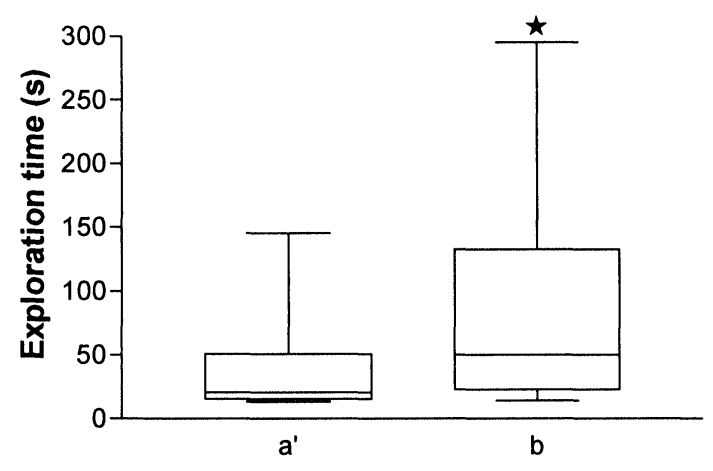

Fig. 1: The exploration of the familiar object (a') and the novel object (b) in the test trial of the object recognition procedure. Median, $25^{\text {th }}$ and $75^{\text {th }}$ percentile, and range are shown. *significantly different from the exploration of the familiar object, $p<0.05$.

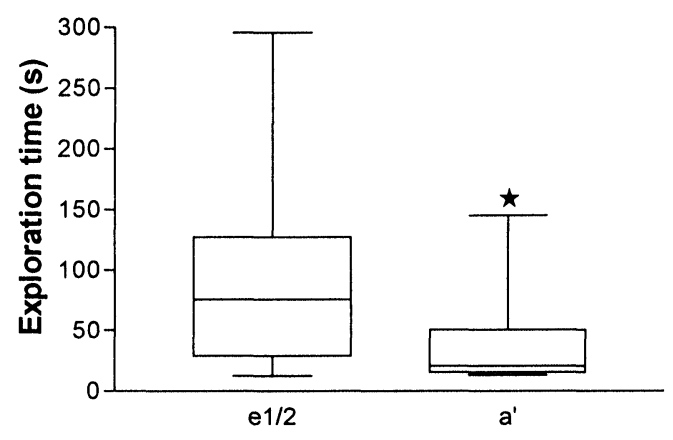

Fig. 2: The exploration of the familiar object in the sample trial (e1/2) and the test trial (a') of the object recognition procedure. The exploration of the familiar object in the sample trial (e1/2) was calculated as half of the total exploration in the sample trial. Median, $25^{\text {th }}$ and $75^{\text {th }}$ percentile, and range are shown. *significantly different from the exploration of the familiar object in the sample trial, $p<0.05$.
(Fig. 2). Yet, we did not find a significant habituation of the total exploration between the sample trial and test trial as was found in rats (Ennaceur \& Delacour, 1988).

The pigs generally showed a good level of spontaneous exploration of the objects. Large variation between individual pigs was seen in the exploration times. A subgroup of pigs showed very high exploration times; in two instances a pig explored the objects for more than $7 \mathrm{~min}$. Such high exploration times are related to the tendency of some pigs to manipulate the objects with the mouth and snout. We only used boars, as it is our impression that at least adult non-castrated boars are more explorative than sows. We have, however, not confirmed this suggestion by comparing boars and sows in an experiment.

The delay between the sample trial and the test trial was $1 \mathrm{~h}$ in the present experiment. Thus, it can be concluded that the memory for objects lasts for at least $1 \mathrm{~h}$ in pigs after a $10 \mathrm{~min}$ sample trial. By studying the recognition after different delays one could get an indication of how long the memory of objects can be detected in pigs by the object recognition method. In rats a significant recognition of the familiar object has only been found consistently for delays of $1 \mathrm{hr}$ or less (Ennaceur \& Aggleton, 1994). In mice significant recognition has been shown after $24 \mathrm{~h}$ (Dodart et al., 1997). In both rodent species the duration of the recognition effect depends upon the length of the sample trial; the longer the sample trial the longer lasts the exploration difference between the familiar and the novel object, but only up to a certain level (Ennaceur \& Aggleton, 1994; Dodart et al., 1997). The effect of different lengths of the sample trial on the object recognition could also be studied in pigs.

In conclusion, the object recognition paradigm developed for rats by Ennaceur and Delacour may also be used for pigs. By this procedure the testing of spontaneous trial-unique memory in pig models 
of human brain pathology can be performed. The test is also useful for the testing of drug effects on trial-unique memory in pigs.

\section{ACKNOWLEDGEMENTS}

The study was supported by the Lundbeck Foundation, the Novo Nordic Research Foundation, and the H:S Research Foundation.

\section{REFERENCES}

Bollen PJA. 2001. Nutrition of Göttingen minipigs. Ph.D. thesis. Faculty of Health Sciences, University of Southern Denmark, Odense, Denmark.

Dodart JC, Mathis C, Ungerer A. Scopolamine-induced deficits in a two-trial object recognition task in mice. NeuroReport 1997; 8: 1173-1178.

Ennaceur A, Aggleton JP. 1994. Spontaneous recognition of object configurations in rats: effects of fornix lesions. Exp Brain Res; 100: 85-92.

Ennaceur A, Delacour J. 1988. A new one-trial test for neurobiological studies of memory in rats. I: Behavioral data. Behav Brain Res; 31: 47-59.

Harvey PD, Sharma T. 2002. Understanding and Treating Cognition in Schizophrenia: A Clinician's Hand-book. London, UK: Martin Dunitz Ltd.; 177.

Klopfer FD. 1966. Visual learning in swine. In: Bustad LK, McClellan RO, eds, Swine in Biomedical Research. Richland, Washington, USA: Battelle Memorial Institute, Pacific Northwest Laboratory; 559-574.
Laughlin K, Mendl M. 2000. Pigs shift too: foraging strategies and spatial memory in the domestic pig. Animal Behav 60: 403-410.

Mikkelsen M, Moller A, Jensen LH, Pedersen A, Harajehi JB, Pakkenberg H. 1999. MPTP-induced Parkinsonism in minipigs: A behavioral, biochemical, and histological study. Neurotoxicol Teratol 21: 169-175.

Mishkin M, Delacour J. 1975. An analysis of shortterm visual memory in the monkey. J Exp Psychol. Animal Behav Processes 1: 326-334.

Mitchell JB, Laiacona J. 1998. The medial frontal cortex and temporal memory: tests using spontaneous exploratory behaviour in the rat. Behav Brain Res 97: 107-113.

Olton DS, Becker JT, Handelmann GE. 1979. Hippocampus, space, and memory. Behav Brain Sci 2: 313-365.

Pett MA. 1997. Nonparametric Statistics for Health Care Research. Statistics for Small Samples and Unusual Distributions. Thousand Oaks, California, USA: Sage Publications; 307.

Sakoh M, Rohl L, Gyldensted C, Gjedde A, Ostergaard L. 2000. Cerebral blood flow and blood volume measured by magnetic resonance imaging bolus tracking after acute stroke in pigs: comparison with $\left[{ }^{15} \mathrm{O}\right] \mathrm{H}_{2} \mathrm{O}$ positron emission tomography. Stroke 31: 1958-1964.

Spaan PEJ, Raaijmakers JRW, Jonker C. 2003. Alzheimer's disease versus normal ageing: A review of the efficiency of clinical and experimental memory measures. J Clin Exp Neuropsychol 25: 216-233.

Tulving E. Episodic and semantic memory. 1972. In: Tulving E, Donaldson W, eds, Organization of Memory. New York, NY, USA: Academic Press 381-403. 

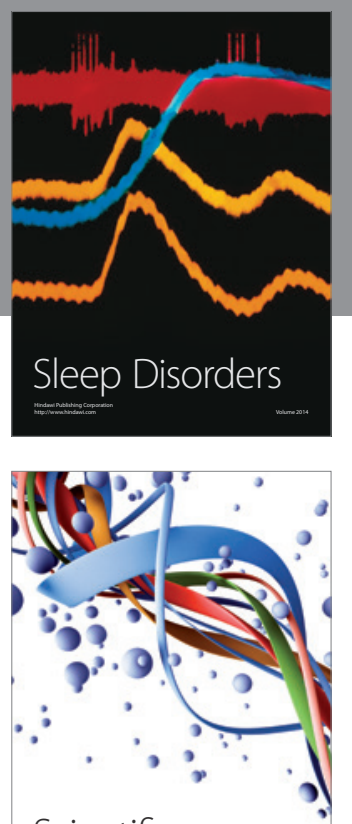

Scientifica
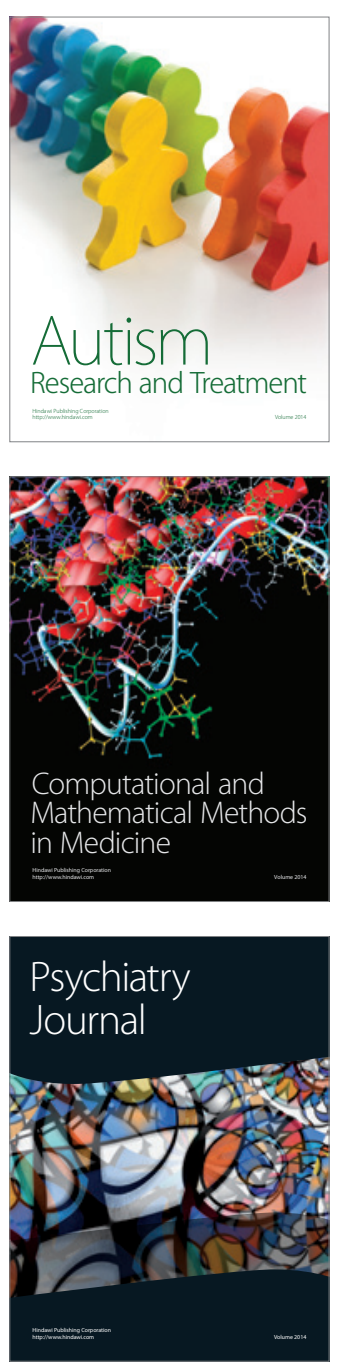
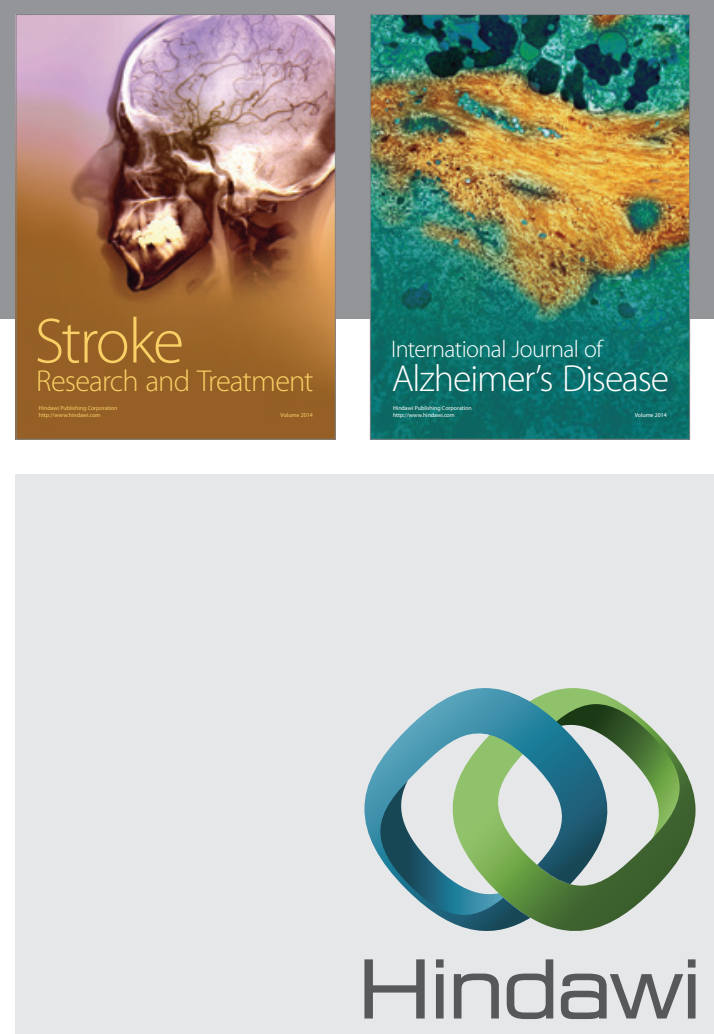

Submit your manuscripts at

http://www.hindawi.com
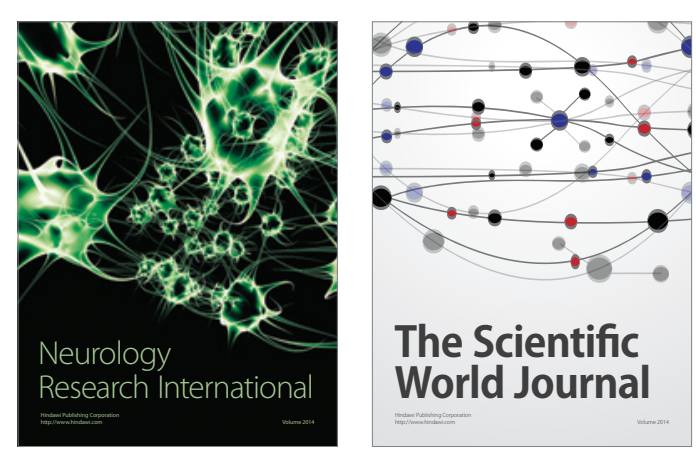

The Scientific World Journal

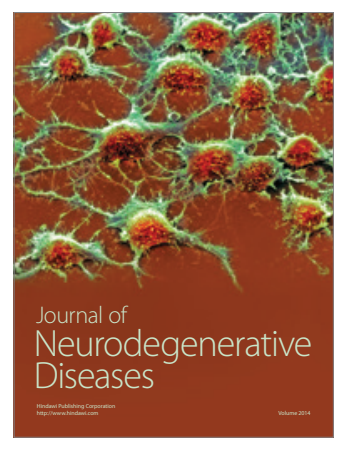

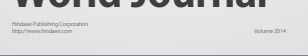

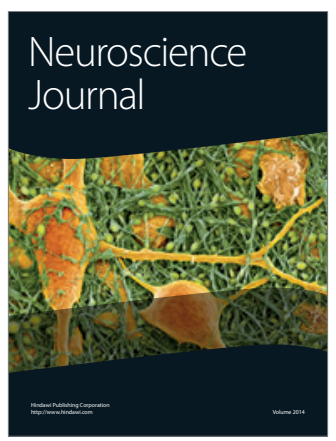

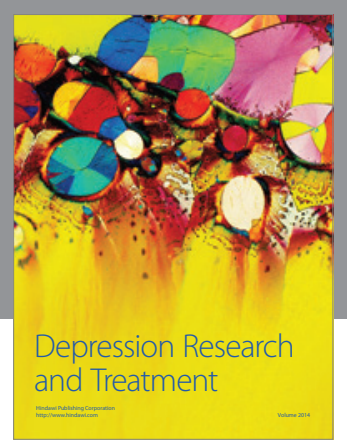
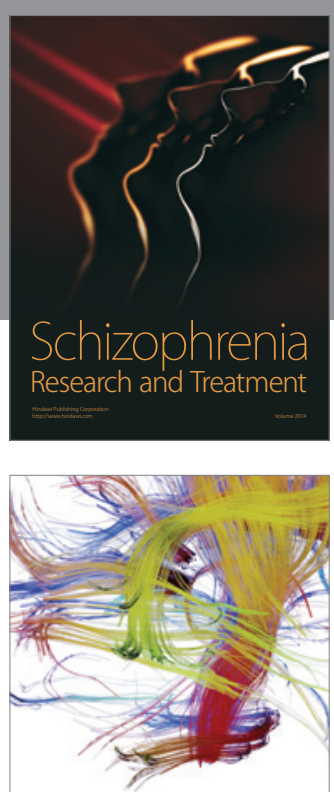

Brain Science

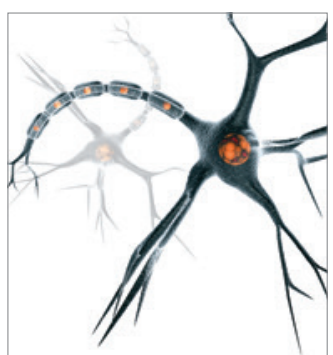

Neural Plasticity
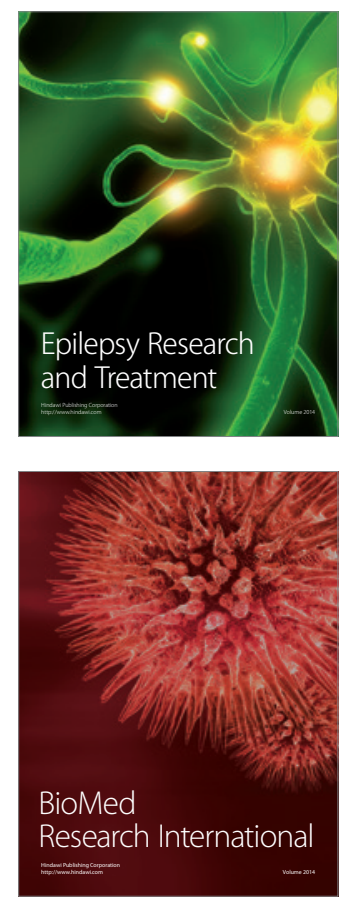

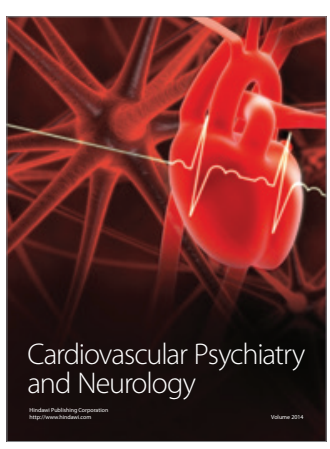

Parkinson's

Disease
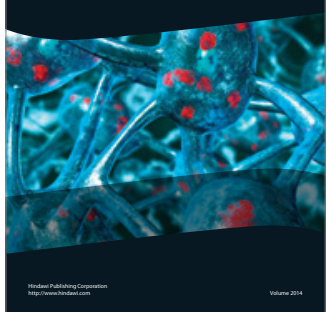